\title{
Using the interconnections and complexities of food systems to teach about human diversity and white privilege
}

COMMENTARY ON RACE AND ETHNICITY IN FOOD SYSTEMS

\author{
Jason S. Parker* \\ University of Vermont
}

Submitted June 15, 2015 / Published online September 17, 2015

Citation: Parker, J. S. (2015). Using the interconnections and complexities of food systems to teach about human diversity and white privilege. Journal of Agriculture, Food Systems, and Community Development, 5(4), 159-163. http://dx.doi.org/10.5304/jafscd.2015.054.022

Copyright (C) 2015 by New Leaf Associates, Inc.

\begin{abstract}
How can diversity courses at land-grant universities be shaped to better prepare the next generation of food systems practitioners, educators, and researchers? This is the question I approach in a discussion of the first undergraduate diversity requirement course in a college of agriculture focusing on domestic issues of race, gender, ethnicity, class, and equity in the development of U.S. food systems. I discuss the benefits I found of using food systems studies as a framework for learning about diversity by highlighting the interconnections among people through discussions of issues every student can appreciate: food and eating.
\end{abstract}

\footnotetext{
* Jason S. Parker, Research Assistant Professor, Department of Plant and Soil Science, University of Vermont; 202 Jeffords Hall; Burlington, Vermont 05401 USA; +1-802-656-2824; jparker7@uvm.edu
}

\section{Keywords}

diversity training, food systems, sustainable agriculture, community engagement, land-grant universities, white privilege

\section{Introduction}

As a white research-track faculty at a predominantly white land-grant university (LGU), I often contemplate the values of teaching a diversity course on U.S. food systems at LGUs. In the last decade, LGUs and liberal arts schools have been preparing many white, middle-class students to move into the food system and "do good." Yet as many have commented on whiteness in the food system, questions arise regarding the benefit derived from these projects. For whom are these people doing "good"? Who has ownership and direction of these projects as they evolve? How are the values of participants represented in these projects? How is privilege challenged or reified in 
the spaces where these projects occur?

These are not questions that I seek to answer in this brief commentary. Rather my aim is to discuss the quality and value of what diversity training at universities could be and how these curricula can be designed to better prepare both minority and dominant group students for fuller, more selfaware participation in our food systems. The issues brought up through a diversity curriculum are important not only for guiding the next generation of practitioners who will graduate into development and outreach positions and will benefit from the enhanced awareness and appreciation for the diversity of people and identities they will encounter, but also for engaging and training the next generation of faculty and researchers. Diversity training at most institutions of higher learning emphasizes international contexts that have paralleled the development of Peace Corps programs, but it has lagged in preparing students to move into domestic service arenas where they are also confronted with issues of diversity. For faculty and staff, preparing the next generation of students for awareness of race, gender, ethnicity, and class perspectives is as important as incorporating these understandings into their own research. Pressing issues of food access, opportunity, and development are interrelated in these issues; anthropologist Roy Rappaport noted (1993) that if we are to affect real change in the world, we need to begin identifying and resolving major problems "at home," as these radiate and affect places near and far. Finally, within this context I also attempt to examine how my own privilege can be directed toward shaping positive change in the food system.

\section{What Does the Next Generation of Practitioners and Educators Need to Know about Diversity?}

If we as faculty at LGUs and other universities and colleges are to provide educational opportunities for students in sustainable food systems, education in all aspects of sustainability needs consideration. LGUs focus well on economic, production, and environmental issues of the food system, but focus less on nurturing an awareness and appreciation for the historical elements of our food system that are shaped by racial, gender, ethnic, and social identities. Roles of people and groups founded on the dominance and subordination of one group over others are directly related to the development and current state of our food system. The historical relationships between minorities and food production in the U.S. are rooted in systemic racial classification that has relied on prejudice, bigotry, and discrimination to endow a dominant white group with privilege over all others. Awareness among students of the nuances of this history is uncommon, in my experience, yet in my opinion is necessary for anyone who plans to move on to work with others toward making change in our food system.

The systems perspective is an entry point for ecological systems and environmental and food justice, labor justice, environmental justice, healthy food access, and nutrition, in addition to organic and local food systems. These areas then can become learning examples for the importance and value of human diversity - life experiences and the intersectionality of individual characteristics that form our identities and yet make a greater whole, and expand our alternatives for growing, sharing, and consuming food. Moreover, they underscore the importance of tradition, new ideas, and novelty in a larger human social system that currently is running a homogenous, overrationalized model of horizontal and vertical integration. Emphasizing alternatives provides new role models beyond the conventional system of agriculture operated by older white men with large farms, and contests ideas of privilege and wholesomeness among white family farms in our food system.

\section{Alternative Views of Agriculture for Students} As Peña (2015) saliently discusses in this issue, many students are taught the traditional tropes of minorities throughout international and U.S. domestic histories (subjugated natives, enslaved and then emancipated Africans, exploited Latino/a workers, etc.). Less common is teaching the histories of people within the context of food systems, a system that is at the core of U.S. social organization and political economy, and highlights the values that a society has for the people who live 
and labor toward producing and consuming food. Understanding the issues and concepts of diversity in complex state-level societies such as the United States can be challenging if taught from a generalized perspective. I find that using the concept of food systems helps contextualize and highlight the characteristics of the relationships among people in that system, which reveals the types of relationships and the effects of power and privilege. A focus on the nuances along the continuum of food production to consumption has the benefit of providing the interconnectedness of a system with the power of self-reflection exercises, such as journaling, pairing and sharing, and response pieces, where students can begin to make their own connections among their social location in the food system with the many other food system actors, the various levels of access in the food system among members of those groups, the power and privilege of each, and the tension between structure and agency in individual and group decision-making.

The lack of appreciation among many policymakers for the interconnectedness of social problems like food deserts with the histories of lowincome and minority communities is problematic. Further, this interconnectedness has resulted in real and perceived barriers to participation among many minority members of society. In large part, this lack of awareness is due to the immensity of the issues stemming from complex and contested histories that are beyond the scope of most many courses. Identifying where privilege originates and how it can be challenged or subverted will prepare undergraduates to identify this privilege in themselves and offer pathways to diffusing it.

\section{Shaping Student Perceptions and Expanding Awareness of Identities}

I teach an undergraduate diversity requirement on U.S. Food Systems, Social Equity and Development. Many have asked me what a diversity course focused on food systems would offer that students would not receive in other diversity requirement courses. At first I was not sure how to answer this. It took time and reflection, and actually teaching the course, to develop what I think is a sound response. As an anthropologist, I believe that the need for food, sex, and belonging are drives that shape humanity and link us to our world. Food, or more specifically, eating, is the submission of the individual to the environment, and society prescribes inclusion and exclusion. Further, food inspires art, creativity, and relationships, and shapes production, economics, and interactions with our environment. Embedding a discussion of human diversity in a food systems course provides entry to the interaction between human perceptions of the self and the natural world, through a subject we each relate to, allowing us to discuss larger systems and the opportunities and constraints in those systems. In this approach, students have the opportunity to look around the system, to see the environmental, economic, and production components, and to locate where people labor in relation to ourselves and our locations.

The approach I take borrows from risk perception literature and my background as a practicing anthropologist. My work in risk perception and socio-cultural anthropology offered me insights for trying to build a learning environment that differentiates among beliefs, attitudes, perceptions, and values held by students, individuals, groups in our readings, and the instructor. I think these distinctions are important as a university diversity course is unlikely to change a student's values, but it can alter perceptions by challenging beliefs and changing attitudes toward a topic, planting the seed for perceiving things differently.

In my experience, we give information and are unable to control how it is perceived or how it will be internalized to either enhance or alter existing beliefs and attitudes; that is a risk we take as educators. This evokes another important aspect of the learning process, the identification of current student knowledge and values. Rather than challenging values directly, I try to focus on challenging beliefs and attitudes that can alter perception with facts. If I begin by challenging a student's values, then all I may achieve is shutting off their learning. Pairing what is known by the students with course content that is new to them can be transformational for some and challenging for others. This long-term growth is essential.

This past semester, I learned that a critical 
event was the shift in our perceptions of who we identify as a farmer. We learned there are many hidden or shadow-farmers whose labor is neither equitably compensated nor recognized and who are often exploited. Understanding the identities of these people and placing them within a system we all participate in helped shift our views away from seeing people as objects on the landscape and toward perceiving them as having goals, values, and desires similar to our own. We focused on ways to shape self-reflection in our readings and assignments to be cognizant that our desire to go into a community "to help" is supported by a social status and privilege affording us the opportunities and (very often) the social and economic freedoms to do this.

Through trial and error in class, I learned from students that emphasizing positive outcomes or positive actions are important no matter how dire the situation. Through reflection pieces, students have shared that negativity influences them to surmise that nothing can be done and leads them to the conclusion that there is little point in trying. Students have also shared their appreciation for my highlighting the importance of incremental change, and that there is value in small, local changes positively affecting people even when the larger system seems unchanged. As for the larger system, I try to impart an urgent need for policy shifts to move beyond individual action. To this end I try to highlight the historic role of information, education, technology, and subsidies (or simply IETS in the diffusion of innovation literature) that has shaped the 150-year development of the current conventional food and farming system. I trace the origin of this development to the 1862 Morrill Act and underscore the structural disadvantages shared across alternative-agriculture farmers.

This diversity requirement, I feel, is the tip of the iceberg of what food systems curriculum should provide students whose goals are "to help." They need to be prepared to understand and partner with the people they want to help, which means being exposed to the histories of diversity and development successes and failures, the need for participatory design and engagement, and the impacts of self-directed programs grounded in the privilege of outreach professionals versus community-based development. They also need concrete examples of the successes of others in these areas.

The big problem that I, and I assume others like me, face is knowing how and where to channel my white academic privilege, and how to coach students to channel their own, toward accomplishing meaningful assistance in partnerships with communities in need while not overstepping, reinforcing, and constructing more privilege. As most would expect, many white students found it difficult to accept the existence of white privilege as the output of systemic racism. Likewise, accepting that racism can extend a system of privilege among well-intended individuals in the food system where whites make judgments and decisions about others in the food system, exacerbating the problem of privilege, was by extension contentious. In negotiating this dilemma, I concede to my students that I have a certain privilege as a white male that my colleagues of other genders and racial categories do not. I am aware of the struggles and burdens of women in academia, and particularly women of color, and the varying degree of respect and gendered assumptions layered upon them by students, colleagues, and administration, specifically but not exclusively from white males. In contrast, I perceive an unspoken, unasked deference and respect from many students in and out of the classroom regardless of race, gender, ethnicity, and social class. Students are often surprised by this, although not all of them, and are interested in discussing it.

Acknowledging our privilege while drawing on our authority as educators can be a way to more comprehensively address diversity issues, challenge privileges in the food system, and construct a learning environment that makes these issues more accessible through interconnected contexts. White faculty and students may not be able to stop the privilege given them, but we can be more aware and better prepared for seeing how it shapes our perceptions, and how those perceptions influence expectations and solutions we may offer in addition to the outcomes we think are fair, just, responsible, and humane. This can allow us to deny this privilege over others in some domains while reflexively using it as a learning example for students. 
Journal of Agriculture, Food Systems, and Community Development ISSN: 2152-0801 online

www.AgDevJournal.com

\section{References}

Peña, O. (2015). Diversity education at land-grant universities from the perspective of a female student of color. Journal of Agriculture, Food Systems, and Community Development. Advance online publication. http://dx.doi.org/10.5304/jafscd. $\underline{2015.054 .020}$

Rappaport, R. (1993). Distinguished Lecture in General Anthropology: The anthropology of trouble. American Anthropologist, 95(2), 295-303. http://dx.doi.org/10.1525/aa.1993.95.2.02a00020 